Mariana Junqueira Suyama

- Thais Cristina Tebaldi

- Cláudia Regina S. Souza Florio

\section{Migração de cateter peridural para o espaço subaracnóideo}

\author{
Instituto Central do Hospital das Clinicas, Faculdade \\ de Medicina da Universidade de São Paulo, São Paulo
}

INTRRDUCุÃa

O bloqueio peridural contínuo, tanto para o uso intraoperatório como para analgesia pós-operatória, vem sendo amplamente utilizado. Essa tendência atual deve-se, entre outros motivos, à menor quantidade total de anestésicos, diminuindo a ocorrência de eventos indesejados relacionados à anestesia. Entretanto, existem complicações inerentes ao procedimento, sendo as mais comuns: dor lombar, punção de dura-máter, injeção intravascular subaracnóidea, formação de hematoma ou abscessos peridurais, meningite, aracnoidite, migração do catéter e lesão neurológica direta.

RELATD DO CASD

Paciente de 70 anos, sexo masculino, P2 (antigo ASA II) (HAS, DM2, DLP). Programação cirúrgica: correção de aneurisma de aorta abdominal infra-renal. Técnica anestésica: peridural contínua e geral endovenosa. Paciente sentado, antissepsia lombar usual com povidine alcoólico, seguida de anestesia da pele e subcutâneo (lidocaína 2\% sem vasoconstritor). Punção peridural em L3-L4 com agulha Tuohy 17 (técnica: perda de pressão). Dose teste (negativa) seguida de infusão de morfina $3 \mathrm{mg}$ e fentanil 150 $\mathrm{mcg}$, em volume total de $10 \mathrm{ml}$. Passagem de cateter peridural $18 \mathrm{G}$, introduzido em $5 \mathrm{~cm}$ sem qualquer sinal de anormalidade. Fixação do cateter e aspiração, sem refluxo de líquido raquidiano ou sangue. Paciente posicionado em DDH, submetido à anestesia geral, com duração da cirurgia de 9 h e 15 min, sem intercorrências. Durante o procedimento cirúrgico não foi administrada qualquer medicação via cateter, que foi mantido para analgesia pós-operatória pela instalação da bomba de PCA. $\mathrm{O}$ paciente foi encaminhado à Unidade de Apoio Cirúrgico. No primeiro PO, em acompanhamento pelo Grupo de Controle de Dor do HCFMUSP, foi realizada aspiração teste do cateter, com refluxo de $10 \mathrm{ml}$ de líquido. Foi levantada a hipótese de localização subaracnóidea e se realizou teste de reação com SFO $9 \%$ e glicose, que mostrou-se positivo. Sem contra-indicaçōes, o cateter foi prontamente retirado, com introdução de PCA endovenosa.

DISCUSSÃa

A migração do catéter peridural é evento comum, amplamente descrito na literatura. Pode trazer conseqüências danosas ao paciente, desde falha anestésica até a ocorrência de intoxicação sistêmica. Está associada à introdução insuficiente do cateter no espaço peridural, tornando-o mais facilmente deslocável à sua inadequada fixação e à mobilização excessiva do paciente no pós-operatório. Faz-se necessário o teste de seu correto posicionamento imediatamente antes de toda infusão anestésica, evitando, desse modo, tais complicaçôes.

REFERÊNCIAS

Poulton B, Young P. A novel method for epidural catheter fixation. Anaesth. 2000, 55(11):1141-42.

2. Day Y, Graham D. Epidural catheter migration. Anaesth. 2002;57(4):418.

Endereço para correspondência:

Mariana Junqueira Suyama

Av. Dr. Enéas de Aguiar, 255

São Paulo (SP) - CEP 05403-900 